\title{
Boraginaceae s.l. A. Juss. em uma área de Caatinga da ESEC Raso da Catarina, BA, Brasil
}

\author{
José Iranildo Miranda de Melo ${ }^{1,3}$ e Wbaneide Martins de Andrade ${ }^{2}$
}

Recebido em 3/01/2006. Aceito em 26/10/2006

\begin{abstract}
RESUMO - (Boraginaceae s.l. A. Juss. em uma área de Caatinga da ESEC Raso da Catarina, BA, Brasil). Este trabalho trata do levantamento florístico-taxonômico da família Boraginaceae em um trecho de Caatinga da Estação Ecológica Raso da Catarina, Bahia, Brasil. Foram encontrados sete espécies e três gêneros de Boraginaceae: Cordia (C. globosa (Jacq.) Kunth, C. leucocephala Moric. e C. rufescens A.DC.), Heliotropium (H. angiospermum Murray e Heliotropium elongatum (Lehm.) I.M. Johnst.) e Tournefortia (T. rubicunda Salzm. ex A.DC. e T. salzmannii DC.). São apresentadas chaves para identificação de gêneros e espécies, além de descrições, ilustrações, comentários, dados de distribuição e hábitat.
\end{abstract}

Palavras-chave: Boraginaceae, florística, taxonomia, Caatinga

\begin{abstract}
Boraginaceae s.l. A. Juss. in the Caatinga of the Raso da Catarina Ecological Station, Bahia State, Brazil). A floristictaxonomic survey of the family Boraginaceae was carried out in a fragment of Caatinga vegetation of the Raso da Catarina Ecological Station, Bahia, Brazil. Seven species and three genera of Boraginaceae were found: Cordia (C. globosa (Jacq.) Kunth; C. leucocephala Moric.; C. rufescens A.DC.), Heliotropium (H. angiospermum Murray; H. elongatum (Lehm.) I.M. Johnst.) and Tournefortia (T. rubicunda Salzm. ex A.DC.; T. salzmannii DC.). Keys to identify genera and species are presented together with descriptions, illustrations, and comments on relationships among these taxa, distribution and habitat.
\end{abstract}

Key words: Boraginaceae, floristics, taxonomy, caatinga vegetation

\section{Introdução}

A Caatinga ocupa uma área de 734.478 km², e é o único bioma exclusivamente brasileiro. Do ponto de vista vegetacional, é bastante diversificada por incluir outros ambientes associados. Somente de Caatingas são reconhecidas 12 tipologias diferentes, as quais despertam atenção especial pelos exemplos fascinantes de adaptação aos hábitats semi-áridos. Isto implica dizer que a relação entre os fatores abióticos como solo-clima-pluviosidade pode explicar, em parte, a grande diversidade de fisionomias aliada à composição florística, com muitas das espécies vegetais endêmicas no bioma. Estima-se que pelo menos 932 espécies foram registradas na região, sendo 380 delas endêmicas (MMA/SBF 2002). Encontramse endemismos também em outros níveis taxonômicos, pois vinte gêneros de plantas são conhecidos apenas na Caatinga (MMA/SBF 2002), dentre os quais se sobressai Auxemma Miers, pertencente à família
Boraginaceae, com apenas duas espécies: A. glazioviana Taub. e A. oncocalyx (Allemão) Baill., restritas, no Brasil, à vegetação de Caatinga. Um outro exemplo de endemismo para esta mesma família, é o de Patagonula bahiensis Moric., encontrada, até o momento, apenas na Caatinga dos estados da Bahia e Minas Gerais (Gottschling \& Miller. 2006).

A família Boraginaceae s.l. reúne cerca de 2.500 espécies em 130 gêneros, com suas representantes distribuídas nas regiões tropicais, subtropicais e temperadas, poucas delas nas zonas temperadas do hemisfério Norte (Al-Shehbaz 1991). Dentre suas espécies, aproximadamente 130 alocadas em 10 gêneros ocorrem no Brasil, dispersas em todas as regiões (Melo inéd.). Podem ser encontrados desde ervas, subarbustos, arbustos, lianas até árvores. Suas folhas são simples, alternas, espiraladas ou não, subopostas ou mais raramente opostas ou verticiladas. As flores são gamopétalas, diclamídeas, pentâmeras, súpero-ovariadas e, apresentam-se reunidas em

\footnotetext{
1 Universidade Federal Rural de Pernambuco, Departamento de Biologia, Programa de Pós-Graduação em Botânica, Rua Dom Manoel de Medeiros s/n, Dois Irmãos, 52171-900 Recife, PE, Brasil

2 Universidade do Estado da Bahia, Campus VIII, Rua da Gangorra 503, 48600-000 Paulo Afonso, BA, Brasil

3 Autor para correspondência: jimmelo@zipmail.com.br
} 
inflorescências paucifloras ou multifloras ou, menos freqüentemente ocorrem isoladamente, na região axilar ou supra-axilar, compondo monocásios folhosos. $\mathrm{O}$ fruto é drupáceo ou esquizocárpico, com duas ou quatro núculas, e representa um importante elemento para delimitação dos seus representantes.

No Brasil, os tratamentos taxonômicos sobre esta família iniciaram-se com Fresenius (1857-1864) para a Flora Brasiliensis. Também incluindo representantes desta família destacam-se, posteriormente, os tratamentos oferecidos por Johnston (1927; 1928; 1930). No entanto, só mais recentemente, outras relevantes contribuições à taxonomia de Boraginaceae foram elaboradas no país; enfocando geralmente floras locais ou consistindo em revisões de cunho genérico: Smith (1970), Guimarães et al. (1971), Taroda (1984), Taroda \& Gibbs (1986a; 1986b; 1987), Vitta (1992), Harvey (1995), Nagatani \& Rossi (2000), Taroda \& Silva (2002), Cavalheiro et al. (2003), Melo \& França (2003), Melo \& Sales (2004, 2005), Ranga et al. (com. pess.), Cavalheiro (dados não publicados), Freitas et al. (dados não publicados) e Melo \& Lyra-Lemos (dados não publicados). Apesar disto, os tratamentos sobre esta família ainda são escassos, especialmente na região Nordeste, onde são estimados 70 espécies e sete gêneros (Melo inéd.). Por esta razão, estudos envolvendo diversidade taxonômica, aliada principalmente à amplitude ecológica se fazem necessários para um melhor entendimento da sistemática e distribuição dos representantes de Boraginaceae s.l.

Este trabalho engloba a família Boraginaceae s.l. em um trecho da Estação Ecológica Raso da Catarina, Bahia, Brasil, tendo por objetivos: a) fornecer chaves de identificação para os gêneros e espécies encontrados; b) prover descrições, ilustrações e comentários sobre afinidades taxonômicas; c) contribuir para o conhecimento da flora da Caatinga, além de d) fornecer, através da realização deste estudo pioneiro, subsídios para elaboração do plano de manejo e desenvolvimento de ações governamentais nesta Unidade de Conservação.

\section{Material e métodos}

Área de Estudo - A ESEC Raso da Catarina está situada à margem esquerda do Rio Vaza Barris e à margem direita do Rio São Francisco a oeste da cidade de Paulo Afonso, nordeste baiano, e abrange uma área de 105.282,00 ha (IBAMA 2005), estendendo-se sob as coordenadas $09^{\circ} 33^{\prime}, 09^{\circ} 54^{\prime} \mathrm{S}$ e $38^{\circ} 29^{\prime}, 38^{\circ} 44^{\prime} \mathrm{W}$.
Limita-se ao norte com a aldeia Pankararé, ao oeste com Rodelas e Canudos, ao sul com Jeremoabo e ao oeste com os municípios de Paulo Afonso e Jeremoabo (IBGE 1985), todos localizados na Bahia. O presente trabalho foi executado em um trecho de Caatinga hiperxerofítica assentado na ESEC Raso da Catarina. O clima é semi-árido, quente, compreendendo o pólo mais seco do Estado, com temperaturas médias que atingem $27{ }^{\circ} \mathrm{C}$. A pluviometria é caracterizada por chuvas irregulares que ocorrem alguns dias do inverno, perfazendo cerca de $400 \mathrm{~mm} / \mathrm{ano}$ (SEMA 1986). A geologia é constituída por rochas sedimentares do cretáceo, caracterizada pela alternância de arenitos e folhetos intercamados em uma estrutura de blocos falhados. Os solos são dos tipos areias quartzosas, planossolo solódio, regossolo distrófico e bruno não cálcico. Esta ESEC encontra-se instalada sobre uma bacia sedimentar no domínio das Caatingas, exibindo fisionomia arbórea, arbustiva e arbustivo-arbórea, raramente ocorrendo matas isoladas (IBAMA 2005).

Tratamento florístico-taxonômico - Este estudo foi desenvolvido no Laboratório de Taxonomia Vegetal e Herbário Professor Vasconcelos-Sobrinho (PEUFR) do Departamento de Biologia, Universidade Federal Rural de Pernambuco, com base em espécimes coletados entre março/2002 e julho/2003. Para o tratamento infragenérico foram consultados os trabalhos de Taroda (1984; 1986a; 1986b; 1987), Johnston (1928; 1930), Förther (1998) e L. Cavalheiro (dados não publicados), além dos protologos. Os nomes dos autores foram padronizados de acordo com Brumitt \& Powell (1992). Os acrônimos dos herbários encontram-se referidos segundo Holmgren et al. (1990). As descrições foram elaboradas com base no roteiro da Flora Fanerogâmica do Estado de São Paulo (FFESP). Para a caracterização das estruturas vegetativas e reprodutivas foi consultada a terminologia de Radford et al. (1974). Os tipos de indumento e venação foram baseados em Payne (1978) e Hickey (1973), respectivamente. Foram elaboradas chaves para identificação de gêneros e espécies utilizando-se caracteres morfológicos, principalmente florais e carpológicos. As ilustrações foram feitas com auxílio de câmara clara acoplada a estereomicroscópio.

\section{Resultados e discussão}

Boraginaceae A. Juss., Gen. pl.: 128. 1789.

Árvores, arbustos, subarbustos, lianas ou ervas anuais ou perenes. Folhas simples, alternas, 
subopostas ou mais raramente opostas, sem estípulas; pecioladas ou sésseis. Inflorescência terminal, falsamente terminal ou axilar, paniculada, gloméruloglobosa, escorpióide ou helicóide. Flores gamopétalas, com ou sem brácteas; corola infundibuliforme, obcampanulada, salverforme, tubular a tubularsalverforme. Estames 5, alternos aos lobos da corola, inseridos geralmente na altura da metade inferior do tubo ou na fauce da corola; anteras livres ou conatas, introrsas ou extrorsas, apendiculadas ou desprovidas de apêndices; deiscência longitudinal. Gineceu 2-carpelar. Ovário 2 ou 4-locular, pela intrusão de um falso septo, súpero. Disco nectarífero discreto ou espessado (apenas em Cordia globosa). Placentação axial ou basal. Óvulos 1-2 por lóculo, anátropos ou hemi-anátropos. Fruto seco ou carnoso, deiscente ou indeiscente, drupáceo ou esquizocárpico, seco, formado por mericarpídios denominados núculas. Sementes 1-2 por loco, embrião plano ou curvo.

No trecho da ESEC estudado foram encontrados três gêneros e sete espécies: Cordia, com três espécies (C. globosa (Jacq.) Kunth, C. leucocephala Moric. e C. rufescens A.DC.), Heliotropium, com duas espécies (H. angiospermum Murray e $H$. elongatum (Lehm.) I.M. Johnst.), e Tournefortia, representado por duas delas (T. rubicunda Salzm. ex A.DC. e T. salzmannii DC.), tratadas a seguir.

\section{Chave para os gêneros}

1. Inflorescência glomérulo-globosa ou paniculada; estigmas 4; fruto com 1 semente 1. Cordia

1. Inflorescência escorpióide; estigma 1; fruto com 2 ou 4 sementes

2. Anteras livres; fruto esquizocárpico, seco, com 2 núculas

2. Heliotropium

2. Anteras conatas; fruto drupáceo, carnoso, com 4 pirênios 3. Tournefortia

1. Cordia L., Sp. pl. 1: 190. 1753.

Espécie típica: C. sebestena L.

Arbustos, eretos, escandentes a subescandentes; ramos hirsutos, estrigosos ou escabrosos, rufos ou não, com lenticelas ou não. Folhas alternas, algumas vezes espiraladas, ou menos frequentemente subopostas, pecioladas. Inflorescência paniculada ou gloméruloglobosa, terminal ou internodal, desprovida de brácteas.
Flores andrógenas ou funcionalmente unissexuais, subsésseis ou sésseis; cálice tubular ou campanulado, às vezes costado, densamente estrigoso a pubescente, sépalas conatas; corola infundibuliforme ou tubularsalverforme, marcescente ou decídua após a antese, esparsamente estrigosa a glabra, lobos suborbiculares, orbiculares ou truncados. Estames sésseis, subsésseis ou com filetes desenvolvidos, epipétalos; anteras livres, introrsas ou extrorsas. Ovário 4-locular, óvulos 1-4; estilete 2 vezes bifurcado; estigmas 4, capitados ou clavados, algumas vezes foliáceos. Fruto drupa, muscilaginoso, cálice persistente e acrescente. Semente 1, embrião plano.

\section{Chave para as espécies de Cordia}

1. Inflorescências paniculadas; cálice rufo 3. C. rufescens

1. Inflorescências glomérulo-globosas; cálice nunca rufo

2. Cálice com lacínios de ápice cirroso; corola 2,5-3,5 mm 1. C. globosa

2. Cálice com lacínios de ápice agudo; corola 13-34 mm 2. C. leucocephala

1. Cordia globosa (Jacq.) Kunth, in Humb., Bonpl. \& Kunth, Nov. Gen. et Sp. 3: 76. 1819.

Varronia globosa Jacq., Enum. Syst. Pl.:14. 1760.

Fig. 1-2

Arbusto, ereto, ca. 1,3 m; ramos estrigosos a escabrosos. Folhas alternas dísticas; lâmina 1,5-5,3×0,6-2 cm, membranácea, lanceolada, ovada a ovado-lanceolada, ápice obtuso a agudo, margem serreada, base aguda a truncada, face adaxial estrigosa, face abaxial tomentosa; pecíolo $0,2-1 \mathrm{~cm}$, hirsuto; venação semicraspedódroma. Inflorescência 0,5-1 cm, terminal e internodal, glomérulo-globosa, congesta; pedúnculo 0,7-2,8 cm, hirsuto. Flores 3-7 mm; cálice 3-3,5 mm, campanulado, lacínios 1-1,5×1 mm, largamente obovados, ápice cirroso; corola 2,5-3,5 mm, infundibuliforme, alva, lobos 1,5-2×0,8-1 mm, truncados; estames 5, sésseis; anteras 1-2 mm, oblongas a lanceoladas; ovário ca. 1,5 mm, piriforme; disco nectarífero 0,8-1 mm espes.; estilete 2,7-3,5 mm; estigmas ca. 0,5 mm, clavados. Drupa ca. $1,5 \mathrm{~mm}$ diâm., globosa. Semente-1 (baseada em Melo \& Sales 2005).

Material examinado: BRASIL. Bahia: Paulo Afonso, 0942'68,9' S, 38 29'49,5' W, 17/V/2003, fl., A.A. Santos 107 (PEUFR). 
Material adicional examinado: BRASIL. Bahia: Ibiraba, 1048'00''S, 42 50'00' W, 23/II/1997, fl., fr., L.P. Queiroz 4801 (HUEFS, PEUFR).

Ocorre no sudeste da Flórida e México, alcançando o nordeste da América do Sul e Antilhas (Miller 1988). No Brasil, encontra-se dispersa na Região Nordeste, em vegetação de Caatinga (Taroda 1984; Taroda \& Gibbs 1986b). É encontrada no interior de vegetação arbustivo-arbórea na área de estudo.

Cordia globosa é morfologicamente semelhante a C. leucocephala Moric., da qual é distinta pelo disco nectarífero espessado na base do ovário e pelo tamanho da corola (13-34 mm em C. leucocephala e 2,5-3,5 mm em C. globosa).

2. Cordia leucocephala Moric., Pl. Nouv. d’Americ. 148: 88. 1846.

Fig. 3-4

Arbusto, ereto, ca. $2 \mathrm{~m}$; ramos velutinos entremeados por indumento híspido com longos tricomas ferrugíneos, lenticelas esbranquiçadas. Folhas alternas dísticas; lâmina 2-5,2×1,1-2,7 cm, membranácea, ovada, elíptica a obovada, ápice agudo, margem serreada, base assimétrica, face adaxial estrigosa, face abaxial tomentosa; pecíolo 5-8 mm, estrigoso; venação craspedódroma. Inflorescência terminal, gloméruloglobosa; pedúnculo 1,6-3,6 cm. Flores 1,4-3,5 cm; cálice 2-6 mm, campanulado, lacínios até $6 \mathrm{~mm}$, denteados, puberulentos, ápice agudo; corola 1,3-3,4 cm, infundibuliforme, alva, lobos suborbiculares; estames com filete de 1,5 mm nas flores longistilas; anteras 1,8-2 mm, oblongas; ovário ca. $2 \mathrm{~mm}$, subgloboso; estilete ca. 1,2 $\mathrm{mm}$ nas flores longistilas; ramos estigmáticos ca. $1 \mathrm{~mm}$, estigmas ca. 1,5-2 $\mathrm{mm}$, foliáceos. Drupa não observada.

Material examinado: BRASIL. Bahia: Paulo Afonso, 4/IV/2003, fl., A.L. Silva 125 (PEUFR).

Cordia leucocephala encontra-se restrita ao Nordeste do Brasil, em vegetação de Caatinga (Taroda 1984; Taroda \& Gibbs 1986b) e em restingas (Melo obs. pess.). Na ESEC Raso da Catarina está associada à Caatinga arbustivo-arbórea. Encontrada com flores em abril.

Esta espécie possui folhas ovadas, elípticas a lanceoladas, de base assimétrica, e caule com lenticelas esbranquiçadas. As inflorescências glomérulo-globosas, com flores de cálice campanulado e corola infundibuliforme são compartilhadas com C. globosa da qual é distinta pelo cálice com lacínios de ápice agudo e corola com 13-34 mm.
3. Cordia rufescens A.DC., Prodr. 9: 476. 1845.

Fig. 5-7

Arbusto, 0,4-1,7 m; ramos sulcados, rufos ou não, vilosos. Folhas alternas espiraladas; lâmina 4,4-15×2,3-7,5 cm, cartácea, discolor, elíptica a obovada, ápice agudo ou arredondado, margem inteira, crenada até denteada apenas na região superior, vilosa, base cuneada, face adaxial estrigilosa, face abaxial tomentosa, rufa; pecíolo 0,3-1,2 cm; venação broquidódroma. Inflorescência 1,5-12,5 cm, panícula terminal, raque híspida, rufa; pedúnculo 1,7-4,8 cm. Flores ca. $4 \mathrm{~cm}$, sésseis; cálice 1-1,2 cm, tomentoso, lacínios 2-2,5×2-3,5 mm, levemente desiguais entre si, largamente ovados a depresso-ovados; corola ca. 3,6 cm, tubular-salverforme, constrição ca. $0,8 \mathrm{~cm}$ da base do tubo, alva, com máculas acastanhadas, externamente estrigilosa, internamente glabrescente, lobos $3 \times 9 \mathrm{~mm}$, orbiculares; estames inseridos a ca. $0,5 \mathrm{~cm}$ da base do tubo, vilosos até a metade do seu comprimento, anteras ca. $3,5 \mathrm{~mm}$, divaricadas, oblongas, filetes 1,3-1,7 cm, dilatados na base; ovário ca. $2 \mathrm{~mm}$, subgloboso, óvulo-1; estilete ca. 1,5 cm, cilíndrico; ramos estigmáticos subcilíndricos, bifurcando-se a ca. 3,7 mm do seu comprimento, estigmas ca. 0,2 mm, capitados. Drupa 1,2-1,9 cm, ovóide, enegrecida. Semente 1, ca. 1,5 cm, arestada, reticulada.

Material examinado: BRASIL. Bahia: Paulo Afonso, 13/XII/2003, fl., fr., J.V. Souza 216 (PEUFR); idem, 5/IV/2003, fr., A.A. Santos 51 (PEUFR); idem, 0949'33,9'"S, 38²9'54,2'W, 27/IV/2003, fr., V.M. Fortes 70 (PEUFR); idem, 0942'68,9''S, 38²9'49,5',W, 1/XI/2003, fr., A.S. Lopes 516 (PEUFR).

Cordia rufescens ocorre apenas no Brasil, nas regiões Nordeste, Sudeste e Sul (Johnston 1930; Taroda 1984; Taroda 1987). No Nordeste, foi registrada nos estados do Ceará e Bahia (Taroda 1984; Taroda $\&$ Gibbs 1987). No trecho estudado, encontra-se associada a ambientes de orla de mata. Encontrada com flor em dezembro e com fruto em abril, novembro e dezembro.

Esta espécie é distinta das espécies de Cordia estudadas pelos ramos geralmente rufos com folhas alternas, espiraladas, aliadas à inflorescência paniculada portando flores com cálice tomentoso, rufo, e pelos frutos ovóides.

2. Heliotropium L., Sp. pl. 1: 130. 1753.

Espécie típica: H. europaeum L. 


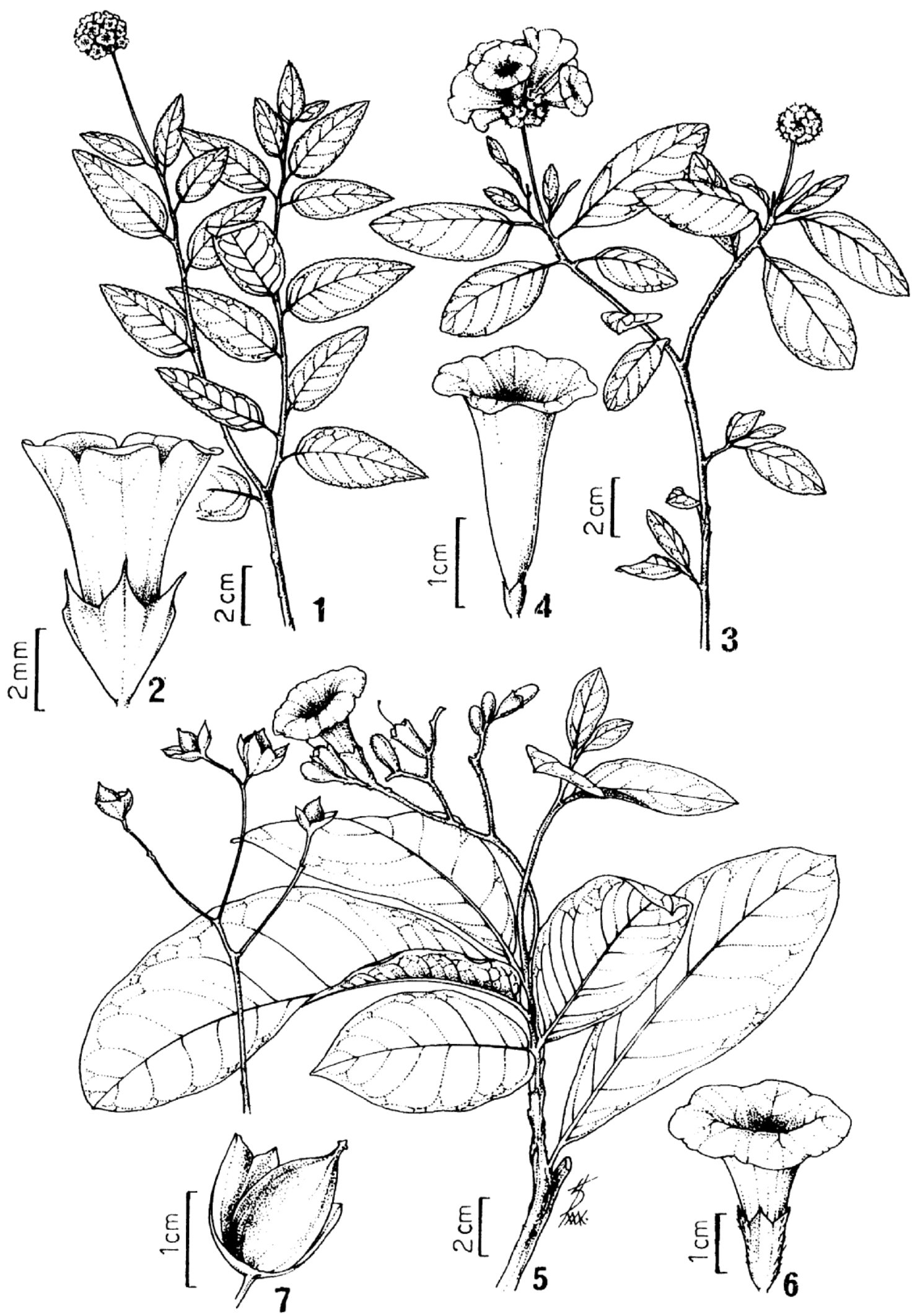

Figuras 1-2. Cordia globosa (Jacq.) Kunth (A.A. Santos 107): 1. Ramo florífero. 2. Flor. Figuras 3-4. Cordia leucocephala Moric. (A.L. Silva 25): 3. Ramo florífero. 4. Flor. Figuras 5-7. Cordia rufescens A.DC. (J.V. Souza 216): 5. Ramo florífero. 6. Flor. 7. Fruto (A.A.S. Lopes 516). 
Ervas ou subarbustos, eretos, decumbentes ou prostrados. Folhas alternas, subopostas ou opostas, sésseis ou pecioladas. Inflorescência escorpióide, terminal, falsamente terminal e/ou axilar, desprovida de brácteas. Flores andróginas, subsésseis ou sésseis; cálice parcialmente unido, com lacínios diferentes entre si; corola alva ou arroxeada, fauce amarela, tubularsalverforme ou obcampanulada, externamente estrigosa, híspida, glabra ou pubescente externamente e internamente, principalmente na fauce; lobos suborbiculares a orbiculares, margem ondulada a ondulado-plicada. Estames subsésseis; anteras introrsas, livres. Ovário 2-locular, algumas vezes 4-locular pela intrusão de um falso septo; óvulos 2 por lóculo; estilete terminal; estigma umbraculiforme ou clavado. Fruto esquizocarpo, duas núculas com duas sementes cada; cálice persistente e acrescente. Sementes oblongo-elípticas ou trígonas.

\section{Chave para as espécies de Heliotropium}

1. Corola obcampanulada; estigma umbraculiforme; frutos depresso-globosos, verruculosos 4. H. angiospermum

1. Corola tubular-salverforme; estigma clavado; frutos mitriformes, híspidos

\section{H. elongatum}

4. Heliotropium angiospermum Murray, Prodr. stirp. götting.: 217. 1770.

Fig. 8-9

Subarbusto, ereto, ca. $70 \mathrm{~cm}$; ramos difusos, fistulosos, esverdeados, estrigosos a escabrosos. Folhas alternas a subopostas; lâmina 2-4×1-2,1 cm, membranácea, discolor, elíptica a ovada, ápice agudo, margem inteira, ciliada, base atenuada, face adaxial escabrosa, face abaxial pubescente; pecíolo 0,4-0,9 cm, atenuado, hirsuto; venação eucamptódroma. Inflorescência 5-7 cm, falsamente terminal e axilar, laxa; pedúnculo 1,2-4,6 cm. Flores 2,8-4 mm, sésseis; cálice 2-2,5×0,4-0,6 mm, externamente seríceo, internamente pubescente a seríceo, lacínios 1,8-2×0,4-0,6 mm, elípticos a estreitamente elípticos, ápice agudo; corola 2,8-4 mm, obcampanulada, alva a arroxeada, lobos 1,3-2×1,2-1,8 mm, eretos, orbiculares, margem ondulada, ápice acuminado. Estames subsésseis, livres; anteras 1-1,4 mm, ovais, ápice apiculado, base levemente cordada. Ovário ca. $0,5 \mathrm{~mm}$, subgloboso; estigma 0,5-0,8 mm, umbraculiforme, séssil. Esquizocarpo ca. $2 \mathrm{~mm}$, depresso-globoso, verruculoso. Sementes 1-1,5 mm, oblongo-elípticas.
Material examinado: BRASIL. Bahia: Paulo Afonso, 09'39'86,5''S, 38²8'25'”W, 13/VII/2003, fl., V.M. Fortes 157 (PEUFR).

Distribui-se desde o sul dos Estados Unidos (Texas e Flórida) e América Central, incluindo Antilhas, até o Brasil. No Brasil, encontra-se dispersa nas regiões Nordeste e Sudeste (Melo \& Sales 2004). Na ESEC Raso da Catarina foi coletada com flores em julho, em borda de mata.

Heliotropium angiospermum pode ser facilmente reconhecida pelo estigma umbraculiforme, séssil, aliado ao fruto depresso-globoso, de superfície verruculosa.

5. Heliotropium elongatum (Lehm.) I.M. Johnst., Contr. Gray Herb. Harv. Univ. 81: 18. 1928.

Tiaridium elongatum Lehm., Asperifolien 1: 16.1818; Ícones 10. t. 6. 1821.

Fig. 10-12

Erva, ereta, $45-80 \mathrm{~cm}$; ramos angulosos, fistulosos, escabrosos ou hirsutos. Folhas alternas a subopostas; lâmina 3,8-6,1×2,1-4 cm, ovada a rômbica, membranácea, ápice acuminado, margem inteira, base oblíqua, face adaxial pubescente, com tricomas aciculiformes, esparsos, entremeados por tricomas menores, face abaxial estrigosa; pecíolo $0,7-1,4 \mathrm{~cm}$, parcialmente alado; venação eucamptódroma. Inflorescência 1-15,2 cm, falsamente terminal e axilar, congesta; pedúnculo 2,2-4,6 cm, hirsuto. Flores 5-7 mm, sésseis; cálice 2-3×0,4-0,5 mm, pubescente a estrigoso externa e internamente, lacínios 1,6-2,3×0,2-0,5 mm, elípticos, estreitamente elípticos a lanceolados ou mais raramente ovados; corola 3,3-7,8 mm, tubularsalverforme, alva ou roxa, híspida, tricomas com duas classes de tamanhos, os maiores aciculiformes entremeados por tricomas menores, ambos hialinos, lobos 1,5-1,7×1,2-1,5 mm, patentes, suborbiculares a orbiculares; estames livres; anteras 1-1,2 mm, oblongas; ovário ca. $0,5 \mathrm{~mm}$, subgloboso; estilete ca. $0,5 \mathrm{~mm}$; estigma ca. 0,4 mm, clavado, com disco espessado na base. Esquizocarpo 3,7-4,5 mm, mitriforme, híspido; núculas costadas. Sementes até $3 \mathrm{~mm}$, trígonas.

Material examinado: BRASIL. Bahia: Paulo Afonso, 14/IV/2003, fl., fr., T.C. Rebouças 08 (PEUFR).

Heliotropium elongatum restringe-se à América do Sul, alcançando Argentina, Bolívia, Paraguai, Uruguai e Brasil (Johnston 1928). No Brasil, H. elongatum se dispersa em todas as regiões (Melo \& Semir com. pess.). Na área de estudo, está associada a ambientes abertos. Encontrada com flores e frutos em abril. 
Caracteriza-se pelo hábito herbáceo, folhas ovadas a rômbicas com pecíolo parcialmente alado e, principalmente, pelo fruto mitriforme, híspido.

3. Tournefortia L., Sp. pl. 1: 140. 1753. Espécie típica: Tournefortia hirsutissima L.

Arbustos ou subarbustos, eretos ou decumbentes, com lenticelas. Folhas alternas ou subopostas, pecioladas. Inflorescência escorpióide, paniculada, terminal, axilar ou internodal, laxa ou congesta. Flores andróginas, subsésseis ou sésseis; lacínios 5, levemente desiguais entre si, persistentes; corola alva ou esverdeada, tubular, com 5 lobos involutos, lineares ou linear-lanceolados. Estames 5, sésseis, epipétalos, anteras conatas, ápice glanduloso-pubescente. Ovário cônico-piramidal ou obclavado, óvulos 2 por lóculo; estilete terminal, cilíndrico; estigma estreitamente cônico ou sub-peltado. Fruto drupáceo, com 4 pirênios, cálice persistente. Semente 1 por pirênio, embrião curvo.

Baseando-se em espécimes de Tournefortia sulamericanos, Johnston (1930) alocou as espécies do gênero em duas seções: Tournefortia seção Tournefortia I.M. Johnst. e Tournefortia seção Cyphocyema I.M. Johnst. As espécies ora abordadas T. rubicunda e $T$. salzmannii, pertencem a esta última seção.

\section{Chave para as espécies de Tournefortia}

1. Folhas concolores; ovário obclavado; estigma sub-peltado 6. T. rubicunda

1. Folhas discolores; ovário cônicopiramidal; estigma estreitamente cônico 5. T. salzmannii

6. Tournefortia rubicunda Salzm. ex A.DC., Prodr. 9: 526.1845.

Fig. 13-17

Arbusto, 1,5-2 m; ramos glabrescentes, com lenticelas esbranquiçadas. Folhas alternas ou subopostas; lâmina 2,5-8,2×0,7-2,7 cm, membranácea, concolor, elíptica a largamente elíptica, ápice agudo, arredondado até emarginado, margem inteira, ciliada, base oblíqua, estrigosa em ambas as faces, tricomas rubicundos, de base acentuadamente discóide; pecíolo 0,7-1,1 cm, sulcado, estrigoso; venação eucamptódroma. Inflorescência 2-4,3 cm, terminal e axilar, laxa; pedúnculo 1,1-1,4 cm, viloso. Flores 4,8-5,5 mm, sésseis a subsésseis; cálice 1,8-2 mm, sépalas desiguais entre si, as externas (duas) maiores e as internas (três) menores, externamente seríceas e internamente pubescentes, lacínios 1,6-1,9×0,4-0,5 mm, lanceolados, externamente pubérulos, internamente glabros; corola 4,8-5,2 mm, constricta na metade inferior do tubo, alvoesverdeada, externamente pubescente, internamente glabrescente, lobos 1,2-1,8×0,1-0,2 mm, lineares; estames inseridos a 2,7-3 $\mathrm{mm}$ da base do tubo, anteras 0,6-1 mm, lanceoladas a ovado-lanceoladas, apiculadas, ovário ca. $1 \mathrm{~mm}$, obclavado; estilete 2-2,3 mm; estigma ca. $0,5 \mathrm{~mm}$, sub-peltado, pubescente, bífido no ápice. Fruto 2-3 mm diâm., subgloboso, glabro ou hirsuto apenas na maturidade. Semente ca. $1,5 \mathrm{~mm}$, lisa, suborbicular.

Material examinado: BRASIL. Bahia: Paulo Afonso, 0942'68,9''S, 38²9'49,5' W, 6/IV/2003, fl., fr., A.S. Lopes 145 (PEUFR); idem, 0942'68,9'S, 38²9'49,5”'W, 8/III/2003, A.S. Lopes 91 (PEUFR).

Material adicional examinado: BRASIL. Pernambuco: Caruaru, E.E. IPA, 19/III/1992, fl., F. Guedes et al. 84 (PEUFR).

Tournefortia rubicunda distribui-se do México à América Central, incluindo Antilhas, e do norte ao oeste da América do Sul (Johnston 1930). No Brasil, ocorre desde o Amazonas e Pernambuco até Rio Grande do Sul (Johnston 1930; L. Cavalheiro, dados não publicados). Na ESEC foi encontrada próxima à base do Ibama e na área do canyon. Coletada com flores e frutos em março e abril.

Esta espécie pode ser seguramente reconhecida com base, principalmente, na lâmina foliar concolor com tricomas rubicundos e, também, pelo ovário obclavado e estigma sub-peltado.

7. Tournefortia salzmannii DC., Prodr. 9: 524. 1845. Fig. 18-22

Subarbusto, decumbente; ramos subcilíndricos, glabros, com lenticelas amarronzadas. Folhas alternas; lâmina 3,3-5,6×1,9-3,1 cm, membranácea, discolor, elíptica até ovada, ápice agudo até obtuso, margem inteira, ciliada, base arredondada, estrigosa na face adaxial, vilosa na face abaxial; pecíolo $0,5-0,7 \mathrm{~mm}$, viloso; venação broquidódroma. Inflorescência 4-4,7 cm, panícula, terminal, laxa, raque vilosa; pedúnculo 1,8-2,6 cm. Flores ca. $5 \mathrm{~mm}$, subsésseis; cálice ca. $3 \mathrm{~mm}$, externamente pubescente ou viloso, internamente glabro, lacínios $2 \times 0,3-0,4 \mathrm{~mm}$, levemente desiguais entre si, lanceolados; corola ca. $5 \mathrm{~mm}$, tubo 2,8-3 mm, constrição a. ca. 0,8 mm da base, externamente seríceo, internamente pubescente, lobos 


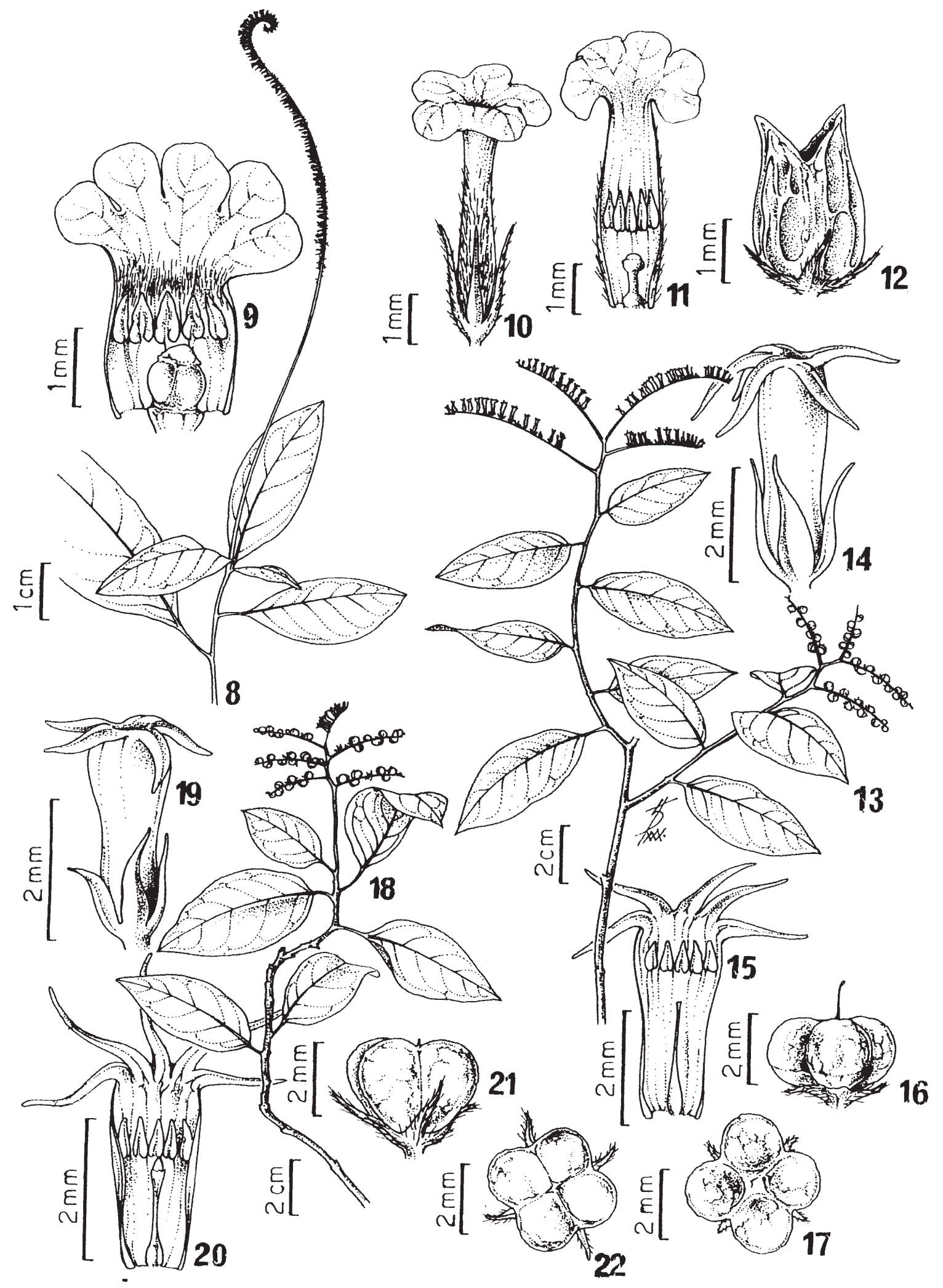

Figuras 8-9. Heliotropium angiospermum Murray (V.M. Fortes 157): 8. Ramo florífero. 9. Corola rebatida. Figuras 10-12. Heliotropium elongatum (Lehm.) I.M. Johnst. (T.C.S. Rebouças 08): 10. Flor. 11. Corola rebatida. 12. Fruto. Figuras 13-17. Tournefortia rubicunda Salzm. ex A.DC. (A.A.S. Lopes 145): 13. Ramo reprodutivo. 14. Flor. 15. Corola rebatida. 16. Fruto em vista lateral. 17. Fruto em vista superior. Figuras 18-22. Tournefortia salzmannii DC. (A.L. Silva 152): 18. Ramo reprodutivo. 19. Flor. 20. Corola rebatida. 21. Fruto em vista lateral. 22. Fruto em vista superior (Andrade-Lima 57-2748). 
2-2,2 mm, lineares, externamente e internamente punctados, ápice castanho; estames inseridos a ca. $2 \mathrm{~mm}$ da base do tubo, anteras ca. $0,8 \mathrm{~mm}$, ovadolanceoladas; ovário ca. $1 \mathrm{~mm}$, cônico-piramidal; estilete ca. $1,5 \mathrm{~mm}$, cilíndrico; estigma ca. $0,5 \mathrm{~mm}$, estreitamente cônico, pubescente, disco espessado. Fruto ca. $3 \mathrm{~mm}$, globoso. Semente $2 \mathrm{~mm}$, depresso-globosa, ventralmente fendida, verruculosa.

Material examinado: BRASIL. Bahia: Paulo Afonso, 0948' 49,8's, 38²9'53,5”W, 5/IV/2003, fl., A.L. Silva 152 (PEUFR).

Material adicional examinado: BRASIL. Pernambuco: Inajá, 20/X/1957, fl., fr., Andrade-Lima 57-2748 (PEUFR).

Esta espécie é encontrada desde o Paraguai, Bolívia e Argentina, alcançando o Brasil (Johnston 1930). No Brasil, distribui-se do Ceará ao Rio de Janeiro (Johnston 1930; L. Cavalheiro, dados não publicados). $\mathrm{Na}$ área de estudo, está associada a ambientes de mata. Encontrada com flores em abril.

Tournefortia salzmannii diferencia-se de T. rubicunda pela lâmina foliar discolor, como também pelo ovário cônico-piramidal e estigma estreitamente cônico.

\section{Agradecimentos}

À Fundação O Boticário de Proteção à Natureza (FBPN), pelo financiamento concedido ao projeto "Levantamento florístico de um trecho de Caatinga na Reserva Ecológica Raso da Catarina - Bahia”, através do processo n. 055220021; a CAPES (Coordenadoria de Aperfeiçoamento de Pessoal de Nível Superior), através da Universidade Federal Rural de Pernambuco, pela bolsa de doutoramento concedida a J.I.M. Melo; a Franck Valdomiro da Silva, pela confecção das ilustrações; ao Instituto de Desenvolvimento Científico e Tecnológico de Xingó, pelo apoio logístico; aos alunos do Herbário Raso da Catarina, pelo auxílio na realização dos trabalhos de campo; à Universidade do Estado da Bahia - UNEB/Campus VIII através da sua Pró-Reitoria de Pesquisa; aos referee pelas valiosas sugestões no manuscrito.

\section{Referências bibliográficas}

Al-Shehbaz, I.A. 1991. The genera of Boraginaceae in the Southeastern United States. Journal of the Arnold Arboretum, Suppl. 1: 1-169.

Atlas Nacional do Brasil: região Nordeste. 1985. Rio de Janeiro, IBGE.
Avaliação e ações prioritárias para a conservação da biodiversidade da Caatinga. 2002. R.M. Pereira et al. (eds.). Universidade Federal de Pernambuco/Fundação de Apoio ao Desenvolvimento/Conservation International do Brasil, Fundação Biodiversitas, EMBRAPA/Semi-Árido. Brasília, Ministério do Meio Ambiente/Secretaria de Biodiversidade e Florestas.

Brumitt, R.K. \& Powell, C.E. 1992. Authors of plant names. London, Royal Botanic Gardens-Kew.

Cavalheiro, L.; Peralta, D.F. \& Furlan, A. 2003. Flórula fanerogâmica da planície litorânea de Picinguaba, Ubatuba, SP, Brasil: Boraginaceae. Hoehnea 30(3): 173-179.

Förther, H. 1998. Die infragenerische Gliederung der Gattung Heliotropium L. und ihre Sterllung innerhalb der subfam. Heliotropioideae (Schrad.) Arn. (Boraginaceae). Sendtnera 5: 35-241.

Fresenius, G. 1857-1864. Cordiaceae, Heliotropieae et Borragineae. Pp. 1-60. In: C.F.P. Martius (ed.) Flora Brasiliensis 9.

Gottschling, M. \& Miller, J.S. 2006. Clarification of the taxonomic position of Auxemma, Patagonula and Saccelium (Cordiaceae, Boraginales). Systematic Botany 31(2): 361-367.

Guimarães, E.F.; Barroso, G.M.; Ichaso; C.L.F. \& Bastos, A.R. 1971. Flora da Guanabara: Boraginaceae. Rodriguésia 38: 194-220.

Harvey, Y.B. 1995. Boraginaceae. Pp. 155-157. In: B.L. Stannard (ed.). Flora of the Pico das Almas, Chapada Diamantina - Bahia, Brazil.

Hickey, L.J. 1973. Classification of the architecture of dicotyledonous leaves. American Journal of Botany 60: $17-33$.

Holmgren, P.K.; Holmgren, N.H. \& Barnett, L.C. 1990. Index Herbariorum, Part I. Ed. 8. The Herbaria of the world, Regnum Veg. New York, New York Botanical Garden, Bronx.

IBAMA 2005. Estação Ecológica Raso da Catarina. http: // www.ibama.gov.br/siucweb/mostraUC. (Acesso em: 17/11/2005).

Johnston, I.M. 1927. Studies in Boraginaceae 6: A Revision of the South American Boraginoideae. Contributions from the Gray Herbarium of Harvard University 78: 3-118.

Johnston, I.M. 1928. Studies in Boraginaceae 7: The South American species of Heliotropium. Contributions from the Gray Herbarium of Harvard University 81: 3-73.

Johnston, I.M. 1930. Studies in Boraginaceae 8: Observations on the species of Cordia and Tournefortia known from Brazil, Paraguay, Uruguay and Argentina. Contributions from the Gray Herbarium of Harvard University 82: 3-89.

Melo, E. \& França, F. 2003. Flora de Grão Mogol, Minas Gerais: Boraginaceae. Boletim de Botânica da Universidade de São Paulo 21(1): 127-129.

Melo, J.I.M. \& Sales, M.F. 2004. Heliotropium L. (Boraginaceae - Heliotropioideae) de Pernambuco, Nordeste do Brasil. Rodriguésia 55(84): 65-87. 
Melo, J.I.M. \& Sales, M.F. 2005. Boraginaceae A. Juss. na região de Xingó: Alagoas e Sergipe. Hoehnea 32(3): 369-380.

Miller, J.S. 1988. A revised treatment of Boraginaceae for Panama. Annals of the Missouri Botanical Garden 75: 456-521.

Nagatani, Y. \& Rossi, L. 2000. Flora Fanerogâmica da Reserva do Parque Estadual das Fontes do Ipiranga -São Paulo, Brasil: 141-Boraginaceae. Hoehnea 27(1): 95-98.

Payne, W.W. 1978. A glossary of plant hair terminology. Brittonia 30: 239-255.

Radford, A.E.; Dickison, W.C.; Massey, J.R. \& Bell, C.R. 1974. Vascular Plant Systematics. New York, Harper \& Row Publishers.

Smith, L.B. 1970. Boragináceas. In: P.R. Reitz. Flora Ilustrada Catarinense. Itajaí, Herbário Barbosa Rodrigues.

Taroda, N. 1984. Taxonomic studies on Brazilian species of Cordia (Boraginaceae). PhD Thesis. University of Saint Andrews, Scotland.
Taroda, N. \& Gibbs, P.E. 1986a. Studies on the genus Cordia L. (Boraginaceae) in Brazil. 1. A new infrageneric classification and conspectus. Revista Brasileira de Botânica 9: 31-42.

Taroda, N. \& Gibbs, P.E. 1986b. A revision of the Brazilian species of Cordia subgenus Varronia (Boraginaceae). Notes from the Royal Botanical Garden of Edinburgh 44: 105-140.

Taroda, N. \& Gibbs, P.E. 1987. Studies on the genus Cordia L. (Boraginaceae) in Brazil. 2. An outline taxonomic revision of subgenus Myxa Taroda. Hoehnea 14: 31-52.

Taroda, N. \& Silva, L.C. 2002. Boraginaceae. In: M.M.R.F. Melo; F. Barros; S.C. Chiea; M. Kirizawa; S.L. JungMendaçolli \& M.G.L. Wanderley (eds.). Flora Fanerogâmica da Ilha do Cardoso (São Paulo, Brasil) 9: 105-114.

Vitta, F.A. 1992. Flora da Serra do Cipó, Minas Gerais: Boraginaceae. Boletim de Botânica da Universidade de São Paulo 13: 235-239. 